\title{
DuPont's OLED material hits million-hour lifetime
}

$\mathrm{D}$ uPont Displays has developed a solution-based green OLED material that has a lifetime of over $1,000,000 \mathrm{~h}$. The company claims its third-generation OLED materials can meet or exceed the performance of today's vapour-deposited materials, and are paving the way for lowcost solution-processed OLED displays.

"Printing OLEDs significantly lowers the cost of manufacturing displays, and with Gen 3 materials technology, display manufacturers can see the material lifetimes and performance required for commercialization," said William Feehery, global business director for DuPont OLED Displays. "With lifetimes five times better than just two years ago, these new materials will allow solution OLEDs to be used in mobile displays, and also to begin to penetrate the television and general lighting markets at a lower cost than today's evaporated OLED technology."

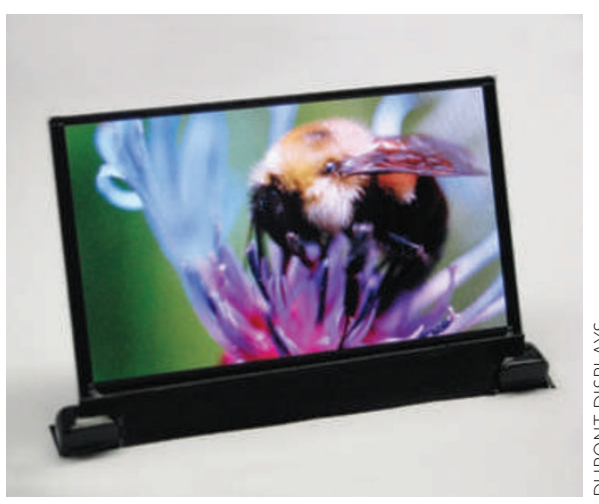

The new Gen 3 green material developed by DuPont has a lifetime of $1,000,000 \mathrm{~h}-\mathrm{a}$ milestone in performance that equates to over 100 years of constant use. This green material demonstrates a light emission efficiency of $25 \mathrm{~cd} \mathrm{~A}^{-1}$ and excellent colour coordinates $(0.26,0.65)$.
Historically, improving the performance of blue light-emitting materials has been the biggest challenge; however, DuPont Gen 3 blue materials are also achieving good results. One of the Gen 3 blue materials has colour coordinates of $(0.14,0.12)$, a light generation efficiency of $6.0 \mathrm{~cd} \mathrm{~A}^{-1}$ and a lifetime of $38,000 \mathrm{~h}$ with an initial brightness of $1000 \mathrm{~cd} \mathrm{~m}^{-2}$. Another blue material has been developed with exceptionally deep blue colour coordinates of $(0.14,0.08)$, an efficiency of $3.9 \mathrm{~cd} \mathrm{~A}^{-1}$ and a lifetime of almost 7,000 h. Owing to its deep blue colour, the lifetime of this material at the luminance required for a $200 \mathrm{~cd} \mathrm{~m}^{-2}$ display is calculated to be approximately $41,000 \mathrm{~h}$.

Furthermore, a high-performing red solution OLED material developed by DuPont has a lifetime of $62,000 \mathrm{~h}$, current efficiency of $13 \mathrm{~cd} \mathrm{~A}^{-1}$ and colour coordinates of $(0.68,0.32)$.

\section{Bayer and Add-Vision sign polymer OLED agreement}

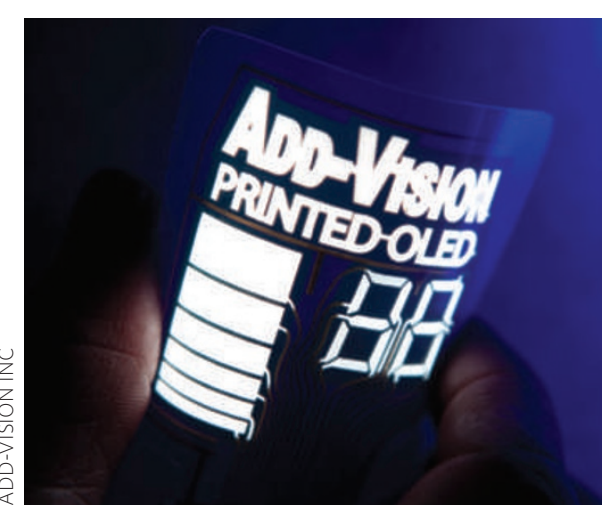

Polymer OLED (P-OLED) developer AddVision Inc has signed a technology and patent license agreement with materials supplier Bayer MaterialScience. The agreement grants Bayer MaterialScience and its affiliates certain rights to manufacture and sell flexible P-OLED displays using Add-Vision's technology and intellectual property portfolio. Financial details, however, have not been disclosed. Karsten Dierksen, vice president and head of the Functional Films Polymer Electronics Unit at Bayer MaterialScience, said: "We are pleased to add this promising technology to our Functional Films portfolio. It's a great fit as it perfectly complements our electroluminescence technology." Matt Wilkinson, Add-Vision's CEO added: "This important agreement with Bayer MaterialScience is the starting point for a strong relationship. Our partner's commitment to film-based technologies and products, combined with the print-based manufacturing expertise of its Functional Films Unit, makes this an ideal collaboration."

Future applications include active packaging and labels, electronic toys and games, as well as point-of-sale signage.

\section{Kodak bags $\$ 1.7$ million lighting project}

A contract worth $\$ 1.7$ million has been awarded to Eastman Kodak by the United States Department of Energy (DOE) for a two-year contract to develop OLED lighting panels. As a pioneer in OLED technology, the Rochester-based company has recently exceeded the project efficiency target set by the DOE of $50 \mathrm{~lm} \mathrm{~W}^{-1}$. Kodak's latest OLED delivers an efficiency of $56 \mathrm{~lm} \mathrm{~W} \mathrm{~m}^{-1}$, a lifetime of $10,000 \mathrm{~h}$, a colour rendering index of 83.6 and a colour temperature of $4,000 \mathrm{~K}$. Kodak says that one of its main objectives now is to reduce manufacturing costs. The firm is developing all-fluorescent and hybrid systems with the aim of achieving longer lifetimes than all-phosphorescent emitter systems. Thanks to its proprietary 'vapour injection source technology', Kodak says that it can reduce manufacturing costs by increasing material utilization and reducing fabrication time. It expects to see a cost reduction of up to $50 \%$ and, ultimately, perhaps even $75 \%$ in the future.

\section{Polytos project to aid organic electronics}

A cluster comprising 27 companies, universities and research institutes in Germany has recently launched the 'printed organic switches and chips' (Polytos) project. Sponsored by the German Federal Ministry of Education and Research and headed by Merck KGaA, the project aims to develop new materials, concepts, components, manufacturing processes and software for printed organic circuits. The consortium says that it is trying to achieve low-cost printed organic circuits that can function as 'smart labels', capable of recording data (such as temperature, humidity or light exposure) on an industrial scale in the future. The project is expected to last three years and cost around $€ 13.8$ million, with $€ 7.2$ million from the German Federal Ministry and $€ 6.6$ million from industry partners.

With the knowledge and involvement of experts ranging from researchers to those in industry, the consortium looks set to help expand Germany's international leadership role in the development of organic electronics. 